\title{
The bright future of dentistry with cold plasma - Review
}

\author{
Dr. Shailja Singh ${ }^{1}$, Dr. Ramesh Chandra ${ }^{2}$, Dr. Supratim Tripathi ${ }^{3}$, \\ Dr. Hena Rahman ${ }^{4}$, Dr. Payal Tripathi ${ }^{5}$, Dr. Amisha Jain ${ }^{6}$, Dr. Pulkit Gupta ${ }^{7}$ \\ ${ }^{I}$ Reader, Career Post Graduate Institute of Dental Sciences \& Hospital Lucknow, UP, INDIA. \\ ${ }^{2}$ Professor, Career Post Graduate Institute of Dental Sciences \& Hospital Lucknow, UP, INDIA \\ ${ }^{3,4,5} \mathrm{Sr}$. Lecturer, Career Post Graduate Institute of Dental Sciences \& Hospital Lucknow, UP, INDIA \\ ${ }^{6,7}$ P. G. Student, Career Post Graduate Institute of Dental Sciences \& Hospital Lucknow, UP, INDIA
}

\begin{abstract}
Plasma is the fourth state of matter and other states of matter are liquid, gas, and solid ${ }^{4}$. Plasma occurs as a natural phenomenon in the universe in the form of fire, in the polar aurora borealis and in the nuclear fusion reactions of the sun and also can be created artificially which has gained importance in the fields of plasma screens or light sources ${ }^{l}$. There are two types of plasma: thermal and non-thermal or cold atmospheric plasma. Thermal plasma has electrons and heavy particles (neutral and ions) at the same temperature. Cold Atmospheric Plasma (CAP) is said to be non-thermal because it has electron at a hotter temperature than the heavy particles that are at room temperature. . Cold Atmospheric Plasma is a specific type of plasma that is less than $104^{\circ} \mathrm{F}$ at the point of application ${ }^{4}$. So the bright future of dentistry with help of cold plasma.
\end{abstract}

Key word:- cold plasma, non thermal atmospheric plasma,

\section{Introduction}

The British physicist Sir William Crookes identified the fourth state of matter in 1879. It was termed "plasma" by Irving Langmuir in 1929. Plasma is a collection of stripped particles. When electrons are stripped from atoms and molecules, those particles change state and become plasma. Plasmas are naturally energetic because stripping electrons takes constant energy. If the energy dissipates, the electrons reattach and the plasma particles become a gas once again ${ }^{1}$. Plasma, referred to as the fourth state of matter. The other states of matter are liquid, gas, and solid (Figure 1) ${ }^{4}$.

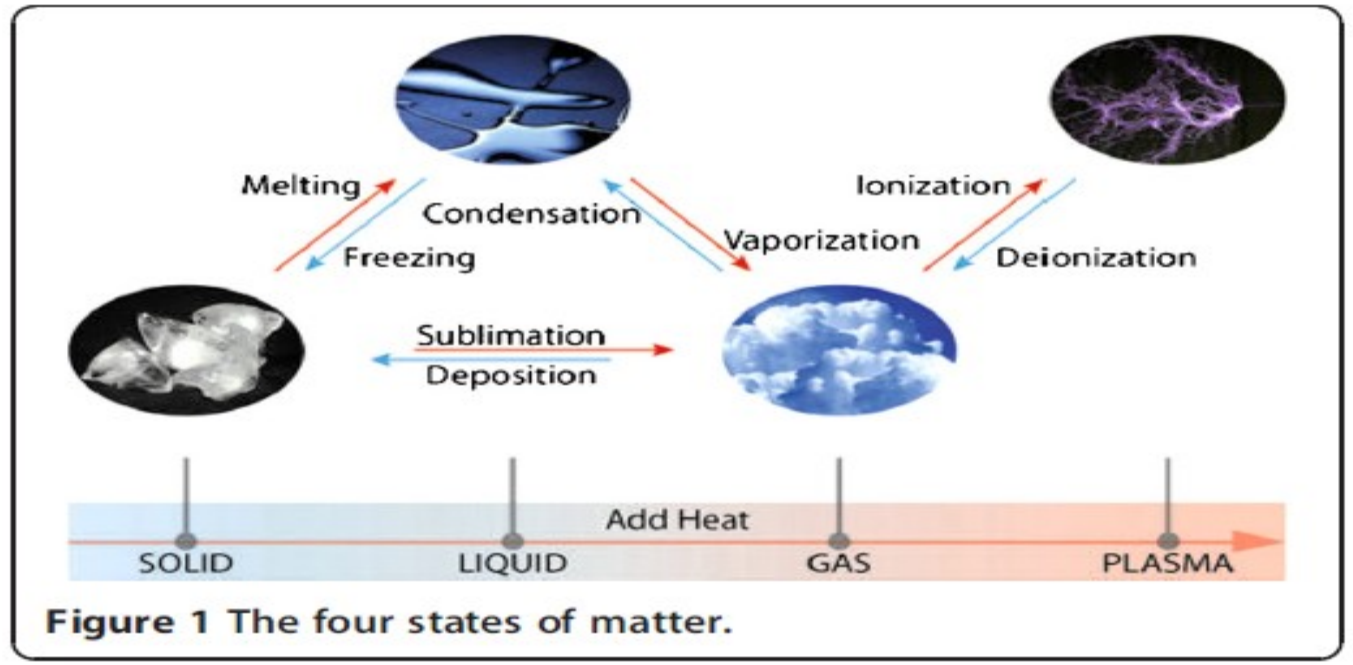

Physical plasma is defined as a gas in which part of the particles are present in ionized form. This is achieved by heating a gas which leads to the dissociation of the molecular bonds and subsequently ionization of the free atoms. Thus, plasma consists of positively and negatively charged ions and negatively charged electrons as well as radicals, neutral and excited atoms and molecules ${ }^{2 \& 3}$

Plasma not only occurs as a natural phenomenon as seen in the universe in the form of fire, in the polar aurora borealis and in the nuclear fusion reactions of the sun but also can be created artificially which has gained importance in the fields of plasma screens or light sources ${ }^{1}$.

There are two types of plasma: thermal and non-thermal or cold atmospheric plasma. Thermal plasma has electrons and heavy particles (neutral and ions) at the same temperature. Cold Atmospheric Plasma (CAP) is 
said to be non-thermal because it has electron at a hotter temperature than the heavy particles that are at room temperature. CAP is a specific type of plasma that is less than $104^{\circ} \mathrm{F}$ at the point of application ${ }^{4}$.

\section{History}

The English physicist Sir William Crookes identified plasmas in 1879, although it was an American physicist, Dr Irving Langmuir who first applied the word 'plasma' to ionized gas in 1929. In the late 1850s, the Siemens company used plasma discharge to generate ozone, which acted as an agent to remove contaminants and toxins from water. Nevertheless, for the next 100 years, little research was conducted exploring the relationship between plasma and biological cells. From the 1960s to 1980s, plasmas were mainly utilized as a secondary agent to indicate biological sterilization, yet diminutive cause and effect knowledge was advanced. It was not until the mid- 1990s that scientists made considerable progress in cold plasma technology. As the news of plasma science spread, visionary researchers took notice and began to explore various ways to utilize plasma's unique properties. Plasma science was in its infancy in the 1990s, but by 1997, multidisciplinary teams set out to understand the effects that plasmas had on pathogenic and nonpathogenic microorganisms, as well as develop proof of concept studies to demonstrate that plasma could be used as a decontaminant or sterilizing agent. Since the late 1990s, plasma research has evolved at a rapid pace as technology expanded into areas, such as biomedical, environmental, aerospace, agriculture and the military ${ }^{5 \& 6}$.

\section{Non Thermal Atmospheric Plasma}

Low temperature plasma, also known as cold plasma, is used in the modification of biomaterial surfaces. It is characterised by a low degree of ionization at low or atmospheric pressure ${ }^{7-9}$. Low temperature plasma is created by the conversion of a compound into gas followed by ionization by applying energy in the form of heat, direct or alternating electric current, radiation or laser light. Oxygen, nitrogen, hydrogen or agon are the commonly used plasma gas sources. In material science, the possible applications of low-temperature plasmas include the modification of surface properties like electrochemical charge or amount of oxidation as well as attachment or modification of surface-bound chemical groups. Consequently, properties like hardness, resistance to chemical corrosion or physical abrasion, wettability, the water absorption capacity as well as the affinity towards specific molecules can be modulated specifically and precisely by the use of low temperature plasmas $^{10}$. Non-thermal Atmospheric Plasmas are very efficient in the deactivation of bacteria. A relatively new area is the use of these plasmas in dental applications. Plasma treatment is potentially a novel tissue-saving technique, allowing irregular structures and narrow channels within the diseased tooth to be cleaned. Lowtemperature plasma is a promising method for destroying microorganisms, an alternative to conventional methods which have numerous drawbacks ${ }^{11}$.

\section{Mechanism Of Generation Of Cold Plasma}

Plasmas can be produced by various means, e.g. radio frequency, microwave frequencies, high voltage ac or dc, etc. The main body of the device is made of a medical syringe and a needle. They are used for guiding the gas flow. The needle also serves as the electrode, which is connected to a high-voltage (HV) submicrosecond pulsed direct-current $(\mathrm{dc})$ power supply (amplitudes of upto $10 \mathrm{kV}$, repetition rate of upto 10 $\mathrm{kHz}$, and pulse width variable from $200 \mathrm{~ns}$ to dc) through a $60-\mathrm{k} \Omega$ ballast resistor $\mathrm{R}$ and a $50-\mathrm{pF}$ capacitor $\mathrm{C}$, where both the resistor and the capacitor are used for controlling the discharge current and the voltage on the needle. Because of the series-connected capacitor and the resistor, the discharge current is limited to a safety range for a human. It is found that, if the resistance of $\mathrm{R}$ is too small or the capacitance of $\mathrm{C}$ is too large, there is feeling of weak electric shock when the plasma is touched by a human [12]. The diameter of the syringe is about $6 \mathrm{~mm}$, and the diameter of the syringe nozzle is about $0.7 \mathrm{~mm}$. The needle has an inner diameter of about $200 \mu \mathrm{m}$ and a length of $3 \mathrm{~cm}$. Working gas such as $\mathrm{He}$, Ar, or their mixtures with $\mathrm{O} 2$ can be used. The gas flow rate is controlled by a mass-flow controller ${ }^{12}$. When working gas such as $\mathrm{He} / \mathrm{O} 2(20 \%)$ is injected into the hollow barrel of the syringe with a flow rate of $0.4 \mathrm{~L} / \mathrm{min}$ and the $\mathrm{HV}$ pulsed dc voltage is applied to the needle, homogeneous plasma is generated in front of the needle. finger can directly contact with the plasma or even with the needle without any feeling of warmth or electric shock. Therefore, this device is safe for the application of root-canal disinfection ${ }^{12}$.

\section{Methods Of Production}

Several different types of CAP have been developed for biomedical uses. Energy is needed to produce and maintain plasma. Thermal, electric, or light energy can be used. Usually, the discharge needed to produce CAP is induced electrically. Some methods used to produce CAP include: Dielectric Barrier Discharge (DBD), Atmospheric Pressure Plasma Jet (APPJ), Plasma Needle, and Plasma Pencil. 


\section{Dielectric Barrier Discharge}

In 1857, Siemens was first to conduct experiments on Dielectric Barrier Discharge (DBD). DBD has many applications including: sterilization of living tissue, bacteria inactivation, angiogenesis, surface treatment, and excimer formation ${ }^{13,14}$. The dielectric barrier discharge (DBD) consists of two flat metal electrodes that are covered with dielectric material. A carrier gas moves between the two electrodes and is ionized to create plasma. One electrode is a high voltage electrode and the other is a grounded electrode. High voltages are required to produce the discharge needed to create the plasma. Alternative Current (AC) high voltages generally drive DBD's with frequencies in the $\mathrm{kHz}$ range. The power consumption is between 10 and $100 \mathrm{~W}^{15}$. There are many variations in the configuration of the electrodes, but the concept behind them all remains the same. For example, some electrodes are cylindrical instead of flat and sometimes the dielectric material covers only one electrode instead of both. More recently, Fridman et al. developed the floating electrode DBD (FE-DBD) ${ }^{16}$. It is similar to the original DBD and consists of two electrodes: an insulated high voltage electrode and an active electrode. The difference between FE-DBD and DBD is that the second electrode is not grounded; it is active meaning that the second electrode can be human skin, a sample, and even an organ. The powered electrode needs to be close to the surface of the second electrode $(<3 \mathrm{~mm})$ to create the discharge. It has been used on endothelial cells, melanoma skin cancer, and blood coagulation. It has also been used in living tissue sterilization and in deactivation of Bacillus stratosphericus (Figure 2) ${ }^{17}$. Plasma jets using a DBD system have also been created $^{18}$

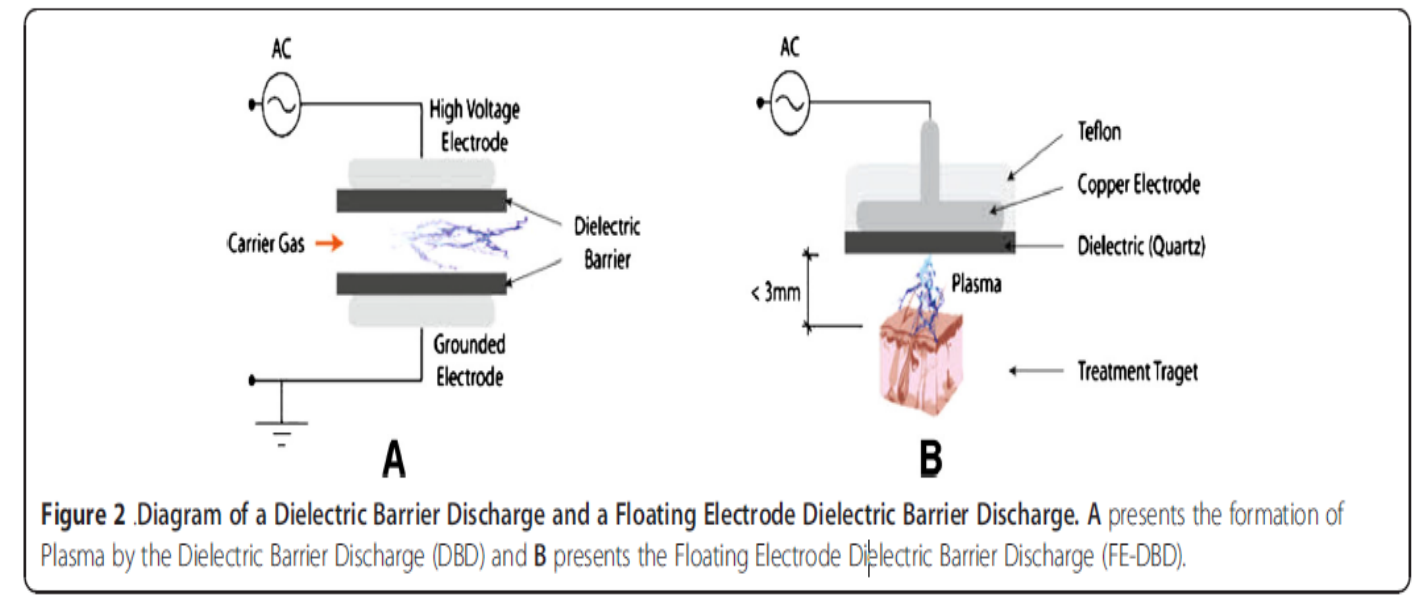

\section{Plasma Jet-Radio Frequency Plasma Jets}

One type of plasma jet, which is employed for bacterial sterilization, is the Atmospheric Pressure Plasma Jet (APPJ) ${ }^{19}$. The APPJ consists of two coaxial electrodes between which a feed gas (mixtures of helium, oxygen, and other gases) flows at a high rate. The outer electrode is grounded while Radio Frequency (RF) power $(50-100 \mathrm{~W})$ at $13.56 \mathrm{MHz}$ is applied to the central electrode that creates a discharge. The reactive species produced exits the nozzle at high velocity and arrives to the area that is to be treated. APPJ has been used for the inactivation of several micro-organisms ${ }^{20-23}$. Koinuma et al. developed the earliest RF cold plasma jet in $1992^{24}$. The cathode is a needle electrode made of tungsten or stainless steel with a $1 \mathrm{~mm}$ diameter connected to a RF source $(13.56 \mathrm{MHz})$. The needle electrode lies within a quartz tube whereas the anode electrode is grounded. Depending on the application, helium or argon was mixed with various gases. This group published several papers describing its variants and applications of the plasma jet ${ }^{25,26}$. In 2002, Stoffels et al. created a miniature atmospheric plasma jet that they called plasma needle ${ }^{27}$ and created a new version in $2004^{28}$. In the former version, the needle was enclosed in a box and as a result, the samples had to be placed inside of the box to be treated. In the new version, the plasma needle consists of a $0.3 \mathrm{~mm}$ metal strand diameter with a sharpened tip inside of a Perspex tube. The length of the entire needle is $8 \mathrm{~cm}$ and $1.5 \mathrm{~cm}$ remains uncovered by the Perspex tube. The gas used most frequently is Helium due to its high thermal conductivity. The gas is then mixed with air at the needle tip where a micro discharge is created. Gases other than Helium are also used ${ }^{29}$. The diameter of the plasma glow generated is $2 \mathrm{~mm}$. Microplasma is created when RF power at $13.05 \mathrm{MHz}$ ranging between $10 \mathrm{~mW}$ and several watts is applied to the needle. Its small size enables it to be used to treat small areas where accuracy is required like in dentistry ${ }^{30,31}$. It has also been used to deactivate E. Coli (Figure 3$)^{32}$. 


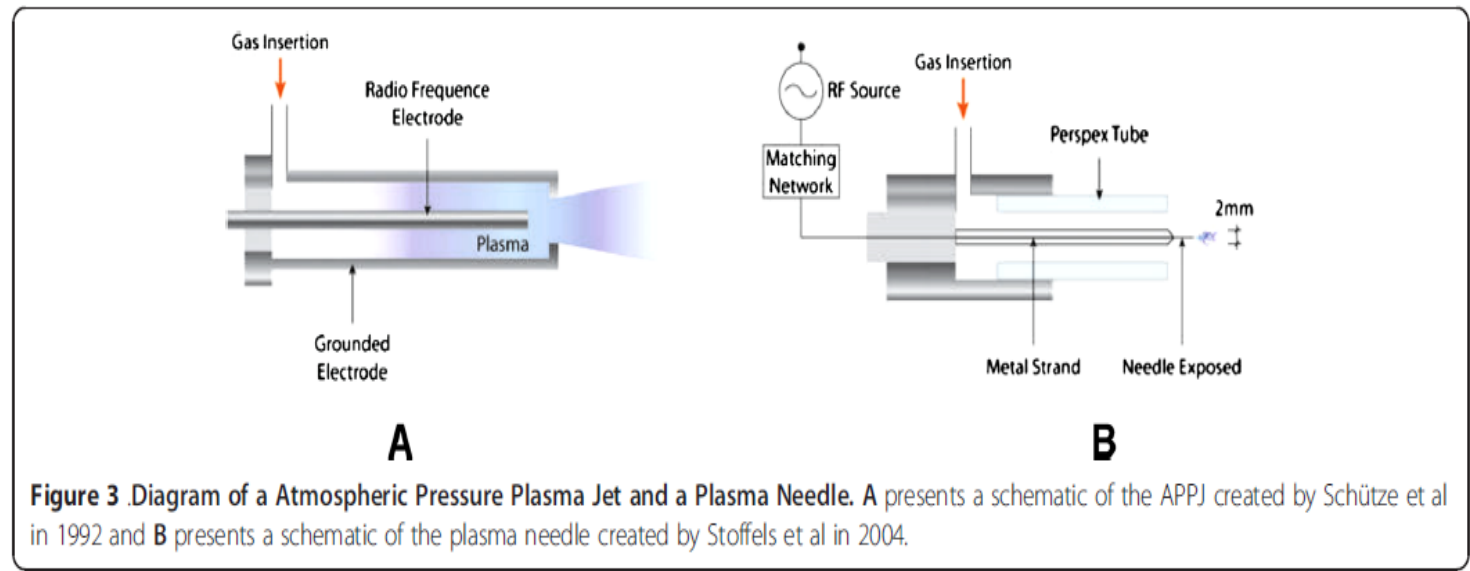

\section{Pulsed Direct Current-Driven Plasma Jets}

Laroussi et al. developed a miniature jet that they called plasma pencil ${ }^{33}$. It consists of a dielectric cylindrical tube of $2.5 \mathrm{~cm}$ in diameter where two disk electrodes of the same diameter as the tube are inserted. The two electrodes are separated by a gap (the distance can vary from 0.3 to $1 \mathrm{~cm}$ ) and consist of a thin copper ring attached to a dielectric disk. To create the plasma, sub-microsecond high voltage pulses are applied between the two electrodes while a gas is injected through the holes of the electrodes. When the discharge is created, a plasma plume is launched through the hole of the outer electrode into the air. Because the plasma plume (up to $5 \mathrm{~cm}$ in length) remains at low temperature $(290 \mathrm{~K})$, it can be touched safely. The electrical power is supplied to the electrodes by a high voltage pulse generator. The high voltage is supplied to the pulse generator by a DC voltage supply with variable output. The plasma pencil has been used in the treatment of E. coli, Leukemia cells, and P. Gingivalis ${ }^{34}$. Forster et al., Zhang et al., and Wash et al. developed a plasma jet using a

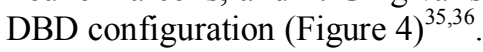

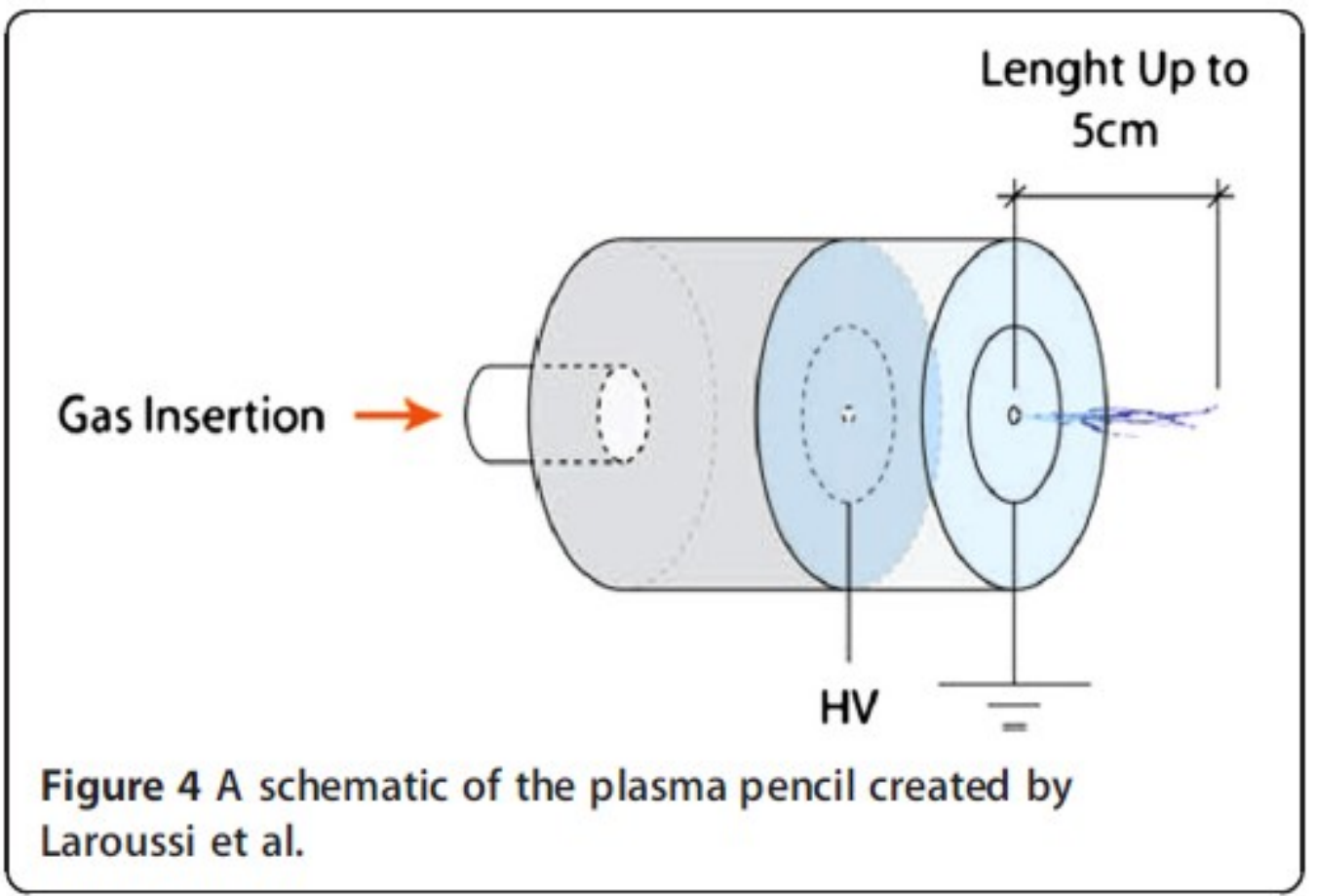

\section{Applications Of Cold Atmospheric Plasma In Dentistry}

Sterilization by eradication of bacteria. The sterilization efficacy of plasma devices is influenced by gas composition, driving frequency, and bacterial strain, but plasma devices have shown to kill a higher proportion of bacteria than do conventional non-thermal methods such as UV sterilization ${ }^{37,38}$. The mechanism of plasma sterilization is related to the abundance of plasma components, like reactive oxygen species, ions and electrons, 
and UV and electromagnetic fields ${ }^{39}$. Also, plasma can affect not only the contacted point but also the area around it. Recently, plasma sterilization has been used to treat dental diseases ${ }^{40}$. The risk of prior transmission through surgical instruments is of both current public and professional concern. The use of plasma decontamination of surgical instruments is limited. Whittaker et al. has indicated that the use of gas plasma cleaning may be extremely beneficial in reducing the absolute amount of proteinaceous materials that may be transferred between patients when endodontic files are reused ${ }^{41}$. Yang Hong Li et al. stated that plasma sterilization, with the advantage of low temperature, fastness, thoroughness, safety, overcomes the deficiency of the traditional sterilization technology, and may become a novel method for killing microbe ${ }^{42}$. Autoclaves and UV sterilizers are presently used to sterilize dental instruments. To develop a dental sterilizer which can sterilize most materials, such as metals, rubbers, and plastics, the sterilization effect of an atmospheric pressure nonthermal air plasma device was evaluated by Su-Jin Sung et al. It was proved that the atmospheric pressure nonthermal air plasma device was effective in killing both Escherichia coli and Bacillus subtilis, and was more effective in killing Escherichia coli than the UV sterilizer ${ }^{43}$.

\section{Plasma In Dental Cavities}

Plasma can treat and sterilize irregular surfaces; making them suitable for decontaminating dental cavities without drilling. Although, plasma itself is superficial, the active plasma species it produces can easily reach inside of the cavity. This approach was pioneered by Eva Stoffels, who suggested the use of plasma needles in the dental cavity on the basis of the ability of plasma to kill Escherichia coli ${ }^{44}$. Goree et al., provided substantial evidence that non thermal atmospheric plasmas killed Streptococcus mutans, a gram-positive cariogenic bacterium $^{45}$. Sladek et al., studied the interactions of the plasma with dental tissue using a plasma needle $\mathrm{e}^{44}$. It is an efficient source of various radicals, which are capable of bacterial decontamination; but, it operates at room temperature and thus, does not cause bulk destruction of the tissue. Raymond EJ et al., studied the interactions of the plasma with dental tissue using a plasma needle. Cleaning and sterilization of infected tissue in a dental cavity or in a root canal can be accomplished using mechanical or laser techniques. However, with both approaches, heating and destruction of healthy tissue can occur. A plasma needle is an efficient source of various radicals, which are capable of bacterial decontamination; however, it operates at room temperature and thus, does not cause bulk destruction of the tissue. From his research he concluded that plasma treatment is potentially a novel tissue-saving technique, allowing irregular structures and narrow channels within the diseased tooth to be cleaned ${ }^{11}$.

\section{Intraoral Diseases}

Oral candidiasis includes Candida-associated denture stomatitis, angular stomatitis, median rhomboid glossitis, and linear gingival erythema. Koban et al. and Yamazaki et al. reported the high efficiency of Candida albicans sterilization using various plasmas. Their result indicates the possibility that stomatitis caused by Candida albicans can be cured by plasma jets ${ }^{46,47}$.

\section{Root Canal Sterilisation}

Lu et al., used a reliable and user-friendly plasma-jet device, which could generate plasma inside the root canal. The plasma could be touched by bare hands and directed manually by a user to place it into root canal for disinfection without causing any painful sensation. When $\mathrm{He} / \mathrm{O}_{2}(20 \%)$ is used as working gas, the rotational and vibrational temperatures of the plasma are about $300 \mathrm{~K}$ and $2700 \mathrm{~K}$, respectively. The peak discharge current is about $10 \mathrm{~mA}$. Preliminary inactivation experiment results showed that it can efficiently kill Enterococcus faecalis, one of the main types of bacterium causing failure of root-canal treatment in several minutes $^{48}$. Pan et al., investigated the feasibility of using a cold plasma treatment of a root canal infected with Enterococcus faecalis biofilms in-vitro. It was concluded that the cold plasma had a high efficiency in disinfecting the Enterococcus faecalis biofilms invitro dental root canal treatment.

\section{Use of Plasma in Composite Restorations}

Preliminary data has also shown that plasma treatment increases bonding strength at the dentin/ composite interface by roughly $60 \%$, and with that interface-bonding enhancement to significantly improve composite performance, durability, and longevity. Current clinical practice relies on mechanical bonding when it should rely on chemical bonding. The culprit that foils mechanical methods is a protein layer, the so-called "smear layer," which is primarily composed of type I collagen that develops at the dentin/adhesive junction. To create a porous surface that the adhesive can infiltrate, current preparation techniques etch and demineralise dentin. Interactions between demineralised dentin and adhesive gives rise to the smear layer, which actually inhibits adhesive diffusion throughout the prepared dentin surface. This protein layer may be responsible, in part, for causing premature failure of the composite restoration. It contributes to inadequate bonding that can leave exposed, unprotected collagen at the dentin- adhesive interface, allowing bacterial enzymes to enter and 
further degrade the interface and the tissue ${ }^{11}$. Kong et al., investigated the plasma treatment effects on dental composite restoration for improved interface properties and their results showed that atmospheric cold plasma brush (ACPB) treatment can modify the dentin surface and thus increase the dentin/adhesive interfacial bonding. The solution is to introduce bonds that depend on surface chemistry rather than surface porosity ${ }^{49}$.

\section{Plasma In Tooth Bleaching}

A non thermal, atmospheric pressure, helium plasma jet device was developed to enhance the tooth bleaching effect of hydrogen peroxide $\left(\mathrm{H}_{2} \mathrm{O}_{2}\right)$. Combining plasma and improved the bleaching efficacy by a factor of 3 compared with using $\mathrm{H}_{2} \mathrm{O}_{2}$ alone. Tooth surface proteins were $\mathrm{n}_{2} \mathrm{O}_{2}$ oticeably removed by plasma treatment. When a piece of tooth was added to a solution of $\mathrm{H}_{2} \mathrm{O}_{2}$ as a catalyst, production of $\mathrm{OH}$ after plasma treatment was 1.9 times greater than when using $\mathrm{H}_{2} \mathrm{O}_{2}$ alone. It is suggested that the improvement in tooth bleaching induced by plasma is due to the removal of tooth surface proteins and to increased $\mathrm{OH}$ production ${ }^{50}$. Nam et al., used a plasma jet on 40 extracted human molar teeth with intact crowns. The 40 teeth were randomly divided into four groups $(\mathrm{n}=10)$ and were treated with Carbamide peroxide + CAP, Carbamide peroxide + Plasma Arc Lamp (PAC), Carbamide peroxide + diode laser, or Carbamide Peroxide alone (control). They observed CAP was the most effective at bleaching teeth. Moreover, they observed that CAP does not damage the tooth due to its low temperature ${ }^{51}$.Claiborne $\mathrm{D}$ et al., used a plasma plume on extracted human teeth. They observed a statistically significant increase in the whitening of the teeth after exposure to CAP $+36 \%$ hydrogen peroxide gel, compared with $36 \%$ hydrogen peroxide only, in the 10 and 20 min groups. The temperature in both treatment groups remained under $80^{\circ} \mathrm{F}$ throughout the study, which is below the thermal threat for vital tooth bleaching ${ }^{52}$. In a study by Jamali and Evans results revealed that prolonged plasma treatment (without bleaching) removed some blue-stain, but the effect was small ${ }^{53}$. On the contrary, the combination of plasma treatment and bleaching removed most of the blue-stains. It was concluded that vacuum plasma pre-treatment and bleaching showed promise as a way of removing blue-stain.

\section{Post and Core}

Yavrich et al., studied the effects of plasma treatment on the shear bond strength between fiber reinforced composite posts and resin composite for core build- up and concluded that plasma treatment appeared to increase the tensile-shear bond strength between post and composite ${ }^{11}$.

\section{MERITS}

Enables the dentist to perform procedures without shots and pain ${ }^{11}$. Reduces or avoids the use of routinely practiced painful and destructive drilling [12]. Noiseless, painless cavity preparations would be a huge $\operatorname{advance}^{11}$.

\section{SAFE TO USE}

The flame is cool to touch without any feeling of warmth or touch ${ }^{12}$. It operates at room temperature and does not cause bulk destruction of the tissue, being superior to lasers ${ }^{11}$.

\section{LIMITATIONS}

The technique is highly sensitive ${ }^{54}$. It does not work well in cases where amalgam restoration is present in the oral cavity ${ }^{54}$. Cost of the equipment, marketing, maintenance and availability are also some of the issues at present $^{55}$. Plasma needle technology has a long way to go and shall prove its applicability in the days to come $^{54}$.

\section{CONCLUSION}

Based on the above evidence, we can say that CAP has a bright future in dentistry due to its antimicrobial properties and its cell death properties on cells. Studies of CAP showed promising results in tooth bleaching, deactivation of biofilms in teeth, instrument sterilization, and in composite restoration. Nevertheless, progress needs to be made concerning the ideal width and depth of the plume of plasma to enable the treatment to reach lower in teeth. However, more studies need to be performed regarding the mechanism of action.

\section{References}

[1]. Raizer YP. Gas Discharge Physics. Springer, Berlin, Germany; 1997.

[2]. Conrads H, Schmidt M. Plasma generation and plasma sources. Plasma Sources Science and Technology. 2000;9:441-54.

[3]. Hoffmann et al. Medical Gas Research 2013, 3:21

[4]. Laroussi M. The biomedical application of plasma: Santosh kumar ch1, $\mathrm{p}$ sarada2, sampath reddy ch3, surendra reddy m4, nagasailaja dsv Journal of Clinical and Diagnostic Research. 2014 Jun, Vol-8(6): ZE07-ZE10

[5]. A brief history of the development of a new field of research.IEEE Trans Plasma Sci 2008;36:1612-14.

[6]. Laroussi M. Sterilization of contaminated matter with an atmospheric pressure plasma. IEEE Trans Plasma Sci 1996;24: 1188-91.

[7]. Roth JR. Industrial Plasma Engineering. Volume 1: Principles. Institute of Physics Publishing, Bristol, UK; 1995. 
[8]. Roth JR. Industrial Plasma Engineering. Volume 2: Applications to Nonthermal Plasma Processing. Institute of Physics Publishing, Bristol, UK; 2001.

[9]. Hippler R, Kersten H, Schmidt M, Schoenbach KH. Low temperature plasma physics: Fundamental aspects and applications. Wiley-VCH, Weinheim, Germany; 2008.

[10]. Meichsner J, Schmidt M, Wagner HE. Non-thermal Plasma Chemistry and Physics.Taylor \& Francis, London, UK; 2011.

[11]. Smitha T, Chaitanya Babu N. Plasma in Dentistry: An update. IJDA. 2010; 2:210-14.

[12]. Xinpei Lu, Yinguang Cao, Ping Yang, Qing Xiong, Zilan Xiong, Yubin Xian, et al. An RC plasma device for sterilization of root canal of teeth. Plasma Sci. 2009;37:668-7.

[13]. Arjunan KP, Clyne AM: Hydroxyl radical and hydrogen peroxide are primarily responsible for dielectric barrier discharge plasma induced angiogenesis. Plasma Process Polym 2011, 8:1154-1164.

[14]. Chiper AS, Chen W, Mejlholm O, Dalgaard P, Stamate E: Atmospheric pressure plasma produced inside a closed package by dielectric barrier discharge in Ar/CO2 for bacterial inactivation of biological samples. Plasma Sources Sci Technol 2011, 20:10.

[15]. Pietsch GJ: Peculiarities of dielectric barrier discharges. Contrib Plasma Phys 2001, 41:620-628.

[16]. Chirokov A, Gutsol A, Fridman A: Atmospheric pressure plasma of dielectric barrier discharges. Pure Appl Chem 2005, 77:487495 .

[17]. Cooper M, Fridman G, Fridman A, Joshi SG: Biological responses of Bacillus stratosphericus to floating electrode-dielectric barrier discharge plasma treatment. J Appl Microbiol 2010, 109:2039-2048.

[18]. Teschke M, Kedzierski J, Finantu-Dinu EG, Korzec D, Engemann J: Highspeed photographs of a dielectric barrier atmospheric pressure plasma jet. IEEE Trans Plasma Sci 2005, 33:310.

[19]. Schütze A, Jeong JY, Babayan SE, Park J, Selwyn GS, Hicks RF: The atmospheric-pressure plasma jet: a review and comparison to other plasma sources. IEEE Trans Plasma Sci 1998, 26:1685

[20]. Fricke K, Koban I, Tresp H, Jablonowski L, Schröder K, Kramer A, Weltmann K-D, von Woedtke T, Kocher T: Atmospheric pressure plasma: a highperformance tool for the efficient removal of biofilms. PLOS ONE 2012, 7(8):e42539. doi:10.1371/journal.pone.0042539.

[21]. Alkawareek MY, Algwari QT, Gorman SP, Graham WG, O'Connell D, et al: Application of atmospheric pressure nonthermal plasma for the in vitro eradication of bacterial biofilms. FEMS Immunol Med Microbiol 2012, 65:381-384.

[22]. Jiang C, Schaudinn C, Jaramillo DE, Webster P, Costerton JW: In vitro antimicrobial effect of a cold plasma jet against Enterococcus faecalis biofilms. ISRN Dentistry 2012, 2012:295736.

[23]. Matthes R, Bekeschus S, Bender C, Hübner N-O, Kramer A: Pilot-study on the influence of carrier gas and plasma application (open resp. delimited) modifications on physical plasma and its antimicrobial effect against Pseudomonas aeruginosa and Staphylococcus aureus. GMS Krankenhaushygiene Interdisziplinär 2012, 7(1):Doc02. doi:10.3205/dgkh000186.

[24]. Koinuma H, Ohkubo H, Hashimoto T, Inomata K, Shiraishi T, Miyanaga A, Hayashi S: Development and application of a microbeam plasma generator. Appl Phys Lett 1992, 60(7):816-817.

[25]. Inomata K, Aoki N, Koinuma H: Jpn J Appl Phys 1994, 33:197.

[26]. Lee B, Kusano Y, Kato N, Naito K, Horiuchi T, Koinuma H: Oxygen plasma treatment of rubber surface by the atmospheric pressure cold plasma torch. Jpn J Appl Phys 1997, 36(5A):2888-2891.

[27]. Stoffels E, Flikweert AJ, Stoffels WW, Kroesen GMW: Plasma needle: a non-destructive atmospheric plasma source for fine surface treatment of (bio) materials. Plasma Sources Sci T 2002, 4:383-388

[28]. Kieft IE, Laan EPvd, Stoffels E: Electrical and optical characterization of the plasma needle. New J Phys 2004, 6:149

[29]. Li S-Z, Huang W-T, Zhang J, Wang D: Optical diagnosis of an argon/oxygen needle plasma generated at atmospheric pressure. Appl Phys Lett 2009, 94:111501.

[30]. Govil S, Gupta V, Pradhan S: Plasma needle: the future of dentistry. Indian J Basic Appl Med Res 2012, 1(2):143-147.

[31]. Jiang C, Gundersen MA, Schaudinn C, Webster P, Jaramillo DE, Sedghizadeh PP, Costerton JW: An atmospheric pressure nonthermal plasma needle for endodontic biofilm disinfection. IEEE Int Confer Plasma Sci - ICOPS 2011:1-1. doi:10.1109/PLASMA.2011.5993048.

[32]. Sladek REJ, Stoffels E: Deactivation of Escherichia coli by the plasma needle. J Phys D-Appl Phys 2005, 38:1716-1721.

[33]. Laroussi M, Lu X: Room temperature atmospheric pressure plasma plume for biomedical applications. Appl Phys Lett 2005, $87: 113902$.

[34]. Laroussi M, Tendero C, Lu X, Alla S, Hynes WL: Inactivation of bacteria by the plasma pencil. Plasma Processes Polym 2006, $3: 470-473$.

[35]. Foster JE, Weatherford B, Gillman E, Yee B: Underwater operation of a DBD plasma jet. Plasma Sources Sci T 2010, 19(2):025001.

[36]. Zhang J, Sun J, Wang D, Wang X: A novel cold plasma jet generated by atmospheric dielectric barrier capillary discharge. Thin Solid Films 2006, 506:404.

[37]. Mccullagh C, Robertson J, Bahnemann DW, Robertson P (2007) The Application of TiO2 Photocatalysis for Disinfection of Water Contaminated with Pathogenic Micro-Organisms: A Review Res Chem Intermed 33: 359-375.

[38]. Kim GC, Kim GJ, Park SR, Jeon SM, Seo HJ, et al. (2009) Air plasma coupled with antibody-conjugated nanoparticles: a new weapon against cancer. J Phys D: Appl Phys 42: 032005.

[39]. Louroussi M (2005) Low Temperature Plasma-Based Sterilization: Overview and State-of-the-Art. Plasma Process Polym 2: 391400.

[40]. Fridman G, Fridman G, Gutsol A, Shekhter AB, Vasilets VN, Fridman A (2008) Applied plasma medicine. Plasma Process Polym 5: 503-533.

[41]. Whittaker AG, Graham EM, Baxter RL, Jones AC, Richardson PR, et al. (2004) Plasma cleaning of dental instruments. J Hosp Infect 56: 37-41.

[42]. YangHong L, Liu S, Hu T (2013) Application of low-temperature plasma in dental clinical sterilization. Foreign Med Sci Stomatol 40: 483-485.

[43]. Sung SJ, Huh JB, Yun MJ, Myung B, Chang W, et al. (2013) Sterilization effect of atmospheric pressure non-thermal air plasma on dental instruments. J Adv Prosthodont 5: 2-8.

[44]. Sladek REJ, Stoffels E, Walraven R, Tiebeek PJA, Koolhoven RA. Plasma treatment of dental cavities. IEEE Trans Plasma Sci. 2004;32:1540-3.

[45]. Goree J, Liu B, Drake D, Stoffels E (2006) Killing of S. mutans Bacteria Using a Plasma Needle at Atmospheric Pressure. IEEE Trans Plasma Sci 34: 1317-1324.

[46]. Koban I, Matthes R, Hu“bner NO, Welk A, Meisel P, et al. (2010) Treatment of Candida albicans biofilms with low-temperature plasma induced by dielectric barrier discharge and atmospheric pressure plasma jet. New J Phys 12: 073039. 
[47]. Yamazaki H, Ohshima T, Tsubota Y, Yamaguchi H, Jayawardena JA, et al. (2011) Microbicidal activities of low frequency atmospheric pressure plasma jets on oral pathogens. Dent Mater J 30: 384-391.

[48]. Ohl A, Schröder K. Plasma assisted surface modification of biointerfaces. In: Hippler R, Kersten H, Schmidt M \& Schoenbach KH. Low temperature plasma physics: Fundamental aspects and applications. Wiley-VCH, Weinheim, Germany; 2008.

[49]. Kong MG, Kroesen G, Morfill G, Nosenko T, Shimizu T. Plasma medicine: an introductory review. New J Phys. 2011;11:115012.

[50]. Lee H W, Kim G J, Kim J M, Park J K, Lee J K and Kim G C, Tooth bleaching with nonthermal atmospheric pressure plasma. J Endod. 2009; 35:587-91.

[51]. Nam SH, Lee HW, SH Cho JKLEE, Jeon YC, Kim GC. High-efficiency tooth bleaching using non thermal atmospheric pressure plasma with low concentration of hydrogen peroxide. J Appl Oral Sci. 2013;21:265-70.

[52]. Claiborne D, McCombs G, Lemaster M, Akman MA, Laroussi M. Low-temperature atmospheric pressure plasma enhanced tooth whitening: the next-generation technology. Int J Dent Hyg. 2014;12(2):108-14.

[53]. Jamali A, Evans PD. Plasma treatment and bleaching to remove bluestain from lodgepole pine sapwood. Eur J Wood Prod. 2013;71:675-77.

[54]. Somya Govil, Vishesh Gupta, Shobhit Pradhan. Plasma needle: The future of Dentistry. Indian Journal of Basic \& Applied Medical Research. 2012;2:143-7.

[55]. Martin M. From distant stars to dental chairs- Plasmas May Promise Pain-free and durable Restorations. AGD Impact. 2009;37:46. 